\title{
Investigation of Fermentation Regimes for the Production of Low-alcohol and Non-alcohol Beers
}

\author{
Ivan Petelkov', Vesela Shopska', Rositsa Denkova-Kostova², Kristina Ivanova³, Georgi Kostov*, \\ Velislava Lyubenova ${ }^{4}$
}

\author{
1 Department of Wine and Beer Technology, Technological Faculty, University of Food Technologies, 26 Maritza Blvd., \\ 4000 Plovdiv, Bulgaria \\ 2 Department of Biochemistry and Molecular Biology, Technological Faculty, University of Food Technologies, 26 Maritza Blvd., \\ 4000 Plovdiv, Bulgaria \\ ${ }^{3}$ Department of Food Technologies, Institute of Canning and Food Safety, 154 Vasil Aprilov Blvd., 4003 Plovdiv, Bulgaria \\ ${ }^{4}$ Institute of Robotics, Bulgarian Academy of Sciences, P. O. B. 79, 1113 Sofia, Bulgaria \\ *Corresponding author, e-mail: george_kostov2@abv.bg
}

Received: 19 March 2020, Accepted: 16 June 2020, Published online: 11 January 2021

\begin{abstract}
The combination of modified mashing method and arrested fermentation for the production of low-alcohol and non-alcohol beers was studied. Therefore, five regimes for fermentation of wort with reduced fermentable sugar content with top-fermenting yeast strain at low temperatures and pitching rates were investigated. According to the fermentation dynamic results the decrease in the fermentation temperature from $10{ }^{\circ} \mathrm{C}$ to $5{ }^{\circ} \mathrm{C}$ at pitching rate of $10^{9}$ Colony Forming Units $\mathrm{cm}^{-3}\left(\mathrm{CFU} \mathrm{cm}^{-3}\right)$ led to significantly reduced concentrations of ethanol and secondary metabolites in beer. The temperature decrease from $10^{\circ} \mathrm{C}$ to $7^{\circ} \mathrm{C}$ at pitching rate of $10^{7} \mathrm{CFU} \mathrm{cm}{ }^{-3}$ resulted in a decrease in the alcohol concentration and increase in all the secondary metabolite concentrations except for the vicinal diketones concentration. Data show that yeast biomass does not grow at $5{ }^{\circ} \mathrm{C}$ and at inoculum concentration of $10^{7} \mathrm{CFU} \mathrm{cm}{ }^{-3}$, which makes fermentation impossible. Fermentation kinetics using Monod's model supplemented with product inhibition was also investigated. Up to $1.7 \%$ of alcohol accumulates in the beer in some of the variants within 7 days. At low fermentation temperatures, yeast biomass utilizes part of the substrate to maintain its vital activity under stress fermentation conditions, which leads to a reduction in the amount of alcohol synthesized. The synthesis and reduction of the secondary metabolites was delayed compared to conventional beer fermentation. The sensory evaluation of the beers produced showed that the most appealing beer was the one produced at $10^{\circ} \mathrm{C}$ and pitching rate of $10^{9} \mathrm{CFU} \mathrm{cm} \mathrm{cm}^{-3}$.
\end{abstract}

\section{Keywords}

low alcohol beer fermentation regimes, fermentation kinetic, modelling, limited fermentation

\section{Introduction}

Globally, there is a growing interest in the development of new assortments of beer with low-alcohol content. The main reasons for the start of low-alcohol beer production in the $20^{\text {th }}$ century were: the lack of raw materials during the World Wars and the prohibition for manufacture, sale and consummation of alcohol in the United States. At present, the expansion of the assortment of beers with low-alcohol content is motivated mainly by the following reasons: provision to beer consumers of alternative products during their activities or under conditions that are conflicting with alcohol consumption; or promoting beers in countries where alcohol consumption is forbidden due to religious reasons [1-3].
In most of the EU countries low-alcohol content beers are divided into alcohol-free beers (AFBs) containing below $0.5 \%$ alcohol by volume (ABV), and low-alcohol beers (LABs) with no more than $1.2 \% \mathrm{ABV}$. In the United States alcohol-free beer means that there is no alcohol present, while the upper limit of $0.5 \%$ ABV corresponds to the so-called non-alcohol beer or "near-beer" [1].

There are two different main groups of methods for the production of beer with low-alcohol content: physical and biological. The physical methods are based on gentle removal of alcohol from regular beer and the beers produced were with poor quality. The biological approaches 
are based on limited ethanol formation during beer fermentation by changing the mashing regimes, arresting beer fermentation or using special yeast strains [1]. The most widespread biological approach is the combination of the modified mashing method and arrested or stopped fermentation, which is carried out at low temperatures. In these cases, wort with normal $\left(9-13^{\circ} \mathrm{P}\right)$ or reduced initial extract $\left(4-7.5^{\circ} \mathrm{P}\right)$ is usually used $[1,4,5]$. Data showed that the wort composition has a significant effect on the sensorial profile of the finished beer [1, 4-8].

The aim of the present work was to investigate the fermentation regimes for the production of low-alcohol/ non-alcohol beer by using wort with low final attenuation, obtained in our previous studies [9]. A novelty in the present study is the possibility of applying conventional yeast strains and the use of available equipment in the brewing industry. This makes it possible to minimize the cost of producing new beer assortments. The development of kinetic models for the comparison of the different fermentation types allows for numerical assessment of the influence of the individual factors on the fermentation process. Thus, the subjective factor is eliminated, and the obtained models can be used for control and optimization of the fermentation process. This is also an element of originality in the present study.

\section{Materials and methods}

\subsection{Yeast strains}

Beer fermentation was carried out using a top-fermenting dry yeast Saccharomyces cerevisiae Safbrew S-33 (Fermentis, France).

\subsection{Wort}

Wort was produced in $20 \mathrm{~L}$ laboratory scale brewery (Braumeister, Germany). $4.5 \mathrm{~kg}$ malt were mixed with water at a ratio of 1:5. Mashing was conducted by increasing the temperature by $1.5^{\circ} \mathrm{C} / \mathrm{min}$ and by maintaining the following temperature rests: $30 \mathrm{~min}$ at $50^{\circ} \mathrm{C}$ and $60 \mathrm{~min}$ at $77^{\circ} \mathrm{C}$ and $1 \mathrm{~min}$ at $78^{\circ} \mathrm{C}$ [9]. Lautering and boiling were also conducted in the same Braumeister. Boiling duration was approximately $1 \mathrm{~h}$ and Nugget hop granules were added to the wort at the beginning of the process. After the hot trub removal, the wort was cooled to the fermentation temperature. The wort characteristics are given in Table 1.

\subsection{Wort fermentation}

The fermentations were carried in plastic bottles, with a volume of $500 \mathrm{~mL}$, equipped with an airlock system. $400 \mathrm{~mL}$ of wort were placed into the bottles and inoculated
Table 1 Wort carbohydrates [9]

\begin{tabular}{lc}
\hline Parameter & Value \\
\hline Original extract, ${ }^{\circ} \mathrm{P}$ & $11.5 \pm 0.5$ \\
Glucose, $\%$ & $0.6 \pm 0.1$ \\
Fructose, $\%$ & $0.1 \pm 0.025$ \\
Maltose, \% & $3.5 \pm 0.25$ \\
Fermentation degree, $\%$ & 63.5 \\
\hline
\end{tabular}

with a yeast suspension, according to Table 2. The bottles were incubated at constant fermentation temperatures according to Table 2 .

The fermentation temperature in Table 2 was selected based on preliminary data on the behavior of Saccharomyces cerevisiae Safbrew S-33. The data show limitation of alcohol synthesis at temperatures below $10^{\circ} \mathrm{C}$. The data in [1] show that most studies with top-fermenting yeast strains are performed in the temperature range of $0{ }^{\circ} \mathrm{C}$ to $12{ }^{\circ} \mathrm{C}$. In a series of experiments with inoculum concentration of $10^{7}$ Colony Forming Units $\mathrm{cm}^{-3}\left(\mathrm{CFU} \mathrm{cm}{ }^{-3}\right)$, it was found that at $5{ }^{\circ} \mathrm{C}$ the concentration of metabolites was below the sensitivity threshold of the respective methods, therefore no data on the fermentation process are presented.

\subsection{Analytical methods and procedures}

1. Standard methods according to EBC [10]

2. Determination of metabolite concentrations. The aldehyde concentration was determined according to the bisulfite method after simple sample distillation of the beer. The ester concentration was determined by ester saponification with $\mathrm{NaOH}$ after simple sample distillation of the beer. The higher alcohol concentration was determined according to the Komarovsky-Felenberg method after simple sample distillation of the beer [11].

3. Determination of biomass: Biomass concentration was calculated according to [12].

\subsection{Mathematical and statistical analyses}

Mathematical and statistical analyses were made according to Eqs. (1) and (2). The identification of the model parameters was done in Mat Lab environment through a specially developed software system $[13,14]$.

Table 2 Fermentation conditions

\begin{tabular}{lcc}
\hline Variant & Inoculum, $\mathrm{CFU} \mathrm{cm}{ }^{-3}$ & Temperature, $^{\circ} \mathrm{C}$ \\
\hline 1 & & 10 \\
2 & $10^{9}$ & 7 \\
3 & & 5 \\
\hline 4 & $10^{7}$ & 10 \\
5 & & 7 \\
\hline
\end{tabular}




\subsection{Sensory analysis}

Beer sensory evaluation was carried out by a trained, 6-member tasting panel. The scores ranged from 0 (absent) to 10 (extremely strong). The eight attributes assessed were:

1. flowery notes;

2. fruity notes;

3. aroma intensity;

4. aroma purity;

5. body structure;

6. malty tones;

7. carbonization;

8. feeling of alcohol.

Blind-tasting was conducted on all the experimental samples. The results were depicted in a spider plot and the values were expressed as the mean values of the two technological replicates.

$$
\mid \begin{aligned}
& \frac{d B}{d \tau}=\mu B \\
& \frac{d A}{d \tau}=q_{A} B \\
& \frac{d R E}{d \tau}=-\frac{1}{Y_{B / R E}} \frac{d B}{d \tau}-\frac{1}{Y_{A / R E}} \frac{d A}{d \tau} \\
& \frac{d E s t}{d \tau}=Y_{E s t} \mu B \\
& \frac{d H A}{d \tau}=Y_{H A} \mu B \\
& \frac{d A l d}{d \tau}=Y_{A l d} \mu B-k_{A l d} B A l d \\
& \frac{d V D K}{d \tau}=Y_{V D K} \mu B-k_{V D K} B V D K
\end{aligned}
$$

Monod model with product inhibition was written in Eq. (2)

$$
\mu=\mu_{\max } \frac{R E}{K_{S B}+R E+\frac{A^{2}}{K_{S B i}}} ; \quad q_{A}=q_{A \max } \frac{R E}{K_{S E}+R E+\frac{A^{2}}{K_{S E i}}},
$$

where $B$ - biomass concentration, $\mathrm{g} \mathrm{L}^{-1} ; A$ - alcohol concentration (product), $\mathrm{g} \mathrm{L}^{-1} ; R E$ - real extract (substrate), $\mathrm{g} \mathrm{L}^{-1} ; \tau$ - time, h; $Y_{A / R E}, Y_{B / R E}-$ yield coefficients; $\mu$ - specific growth rate, $\mathrm{h}^{-1} ; \mu_{\max }-$ maximal specific growth rate, $\mathrm{h}^{-1} ; q_{A}-$ specific alcohol accumulation rate, $\mathrm{g}(\mathrm{g} \mathrm{h})^{-1}$; $q_{A \max }-$ maximal specific alcohol accumulation rate, $\mathrm{g}(\mathrm{g} \mathrm{h})^{-1}$; Est - ester concentration, $\mathrm{mg} \mathrm{L}^{-1} ; H A$ - higher alcohol concentration, $\mathrm{mg} \mathrm{L}^{-1} ;$ Ald - aldehyde concentration, $\mathrm{mg} \mathrm{L}^{-1}$; $V D K$ - vicinal diketones concentration, $\mathrm{mg} \mathrm{L}^{-1} ; Y_{H A}, Y_{E s t}$,
$Y_{\text {Ald }}, Y_{V D K}$ - yield coefficients of the corresponding metabolites, $\mathrm{mg}(\mathrm{g} \mathrm{h})^{-1} ; k_{A l d}, k_{V D K}$ - reduction coefficients for aldehydes and vicinal diketones, $\mathrm{mg}(\mathrm{g} \mathrm{h})^{-1} ; K_{S B}, K_{S E}$ - Monod constants, $\mathrm{g} \mathrm{L}^{-1} ; K_{S B i}, K_{S E i}$ - inhibition constants, $\mathrm{g} \mathrm{L}^{-1}$.

\section{Results and discussion}

Limiting the fermentation in brewing is most often associated with a fermentation temperature below the optimal for the selected yeast strain. In the present study, it has been chosen to work with a top-fermenting yeast strain whose optimal fermentation temperature is in the range of $15-25^{\circ} \mathrm{C}$.

\subsection{Fermentation at pitching rate of $10^{9} \mathrm{CFU} \mathrm{\textrm {cm } ^ { - 3 }}$ 3.1.1 Fermentation dynamics}

The first series of experiments were conducted at initial biomass concentration of $10^{9} \mathrm{CFU} \mathrm{cm}^{-3}$, which was typical for traditional pale beer. The fermentation temperatures were in the range of $5-10{ }^{\circ} \mathrm{C}$. The data obtained are summarized in Fig. 1.

In variant 1 , synthesis and reduction of the major metabolite groups (esters, aldehydes, higher alcohols and vicinal diketones) were delayed compared to conventional beer fermentation with the same yeast strain [14]. The ester synthesis started at the beginning of the fermentation and reached its peak by the $48^{\text {th }}$ hour. Afterwards, the ester synthesis practically stopped. The obtained beer ester concentration was approximately $30 \mathrm{mg} \mathrm{L}^{-1}$, which was 2 to 4 times lower than the ester concentration in conventional beer [14]. In the low-alcohol beer the concentration of higher alcohols was about $20 \mathrm{mg} \mathrm{L}^{-1}$, which was almost 2-3 times lower than the same parameter of conventional beer produced with the same yeast strain $[13,14]$. An advantage of the low-alcohol fermentation is the low synthesis of carbonyl compounds, which also leads to the reduction of the beer maturation time. In the selected fermentation regime, the aldehyde synthesis was poor and their concentration did not exceed $1.5 \mathrm{mg} \mathrm{L}^{-1}$, which was about 20 times lower than their concentration in conventional beer obtained with the same strain [14]. On the other hand, the maximum concentration of vicinal diketones was 2 to 3 times lower than the one in conventional beer produced with the same yeast strain. The low fermentation temperature restricted the rapid reduction of the vicinal diketones and their concentration remained relatively high at the end of the fermentation - about $0.3 \mathrm{mg} \mathrm{L}^{-1}$. It can be suggested that the low fermentation temperature and low biomass concentration were the main reasons for the increase in the vicinal diketones concentration. 


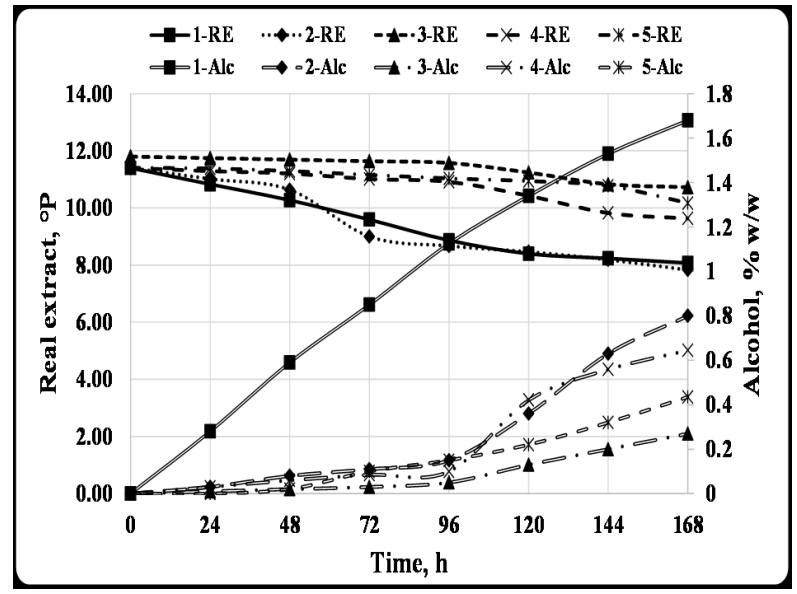

(a)

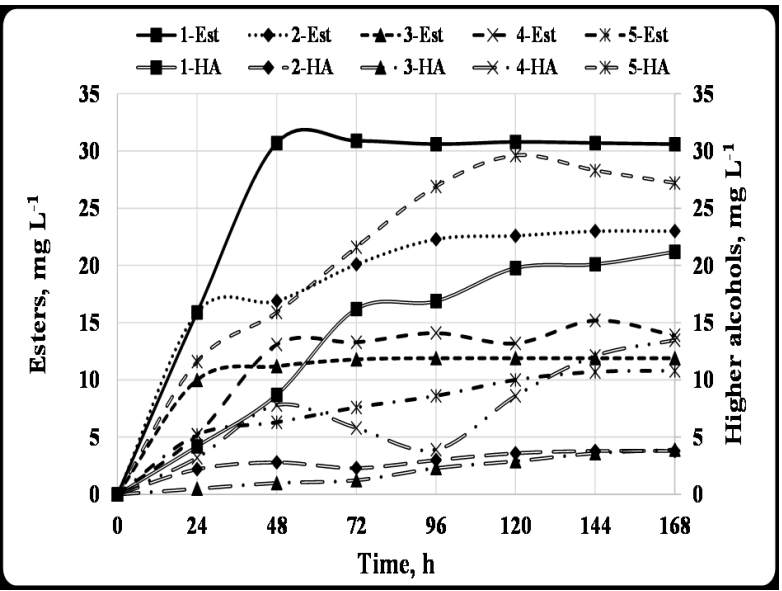

(c)

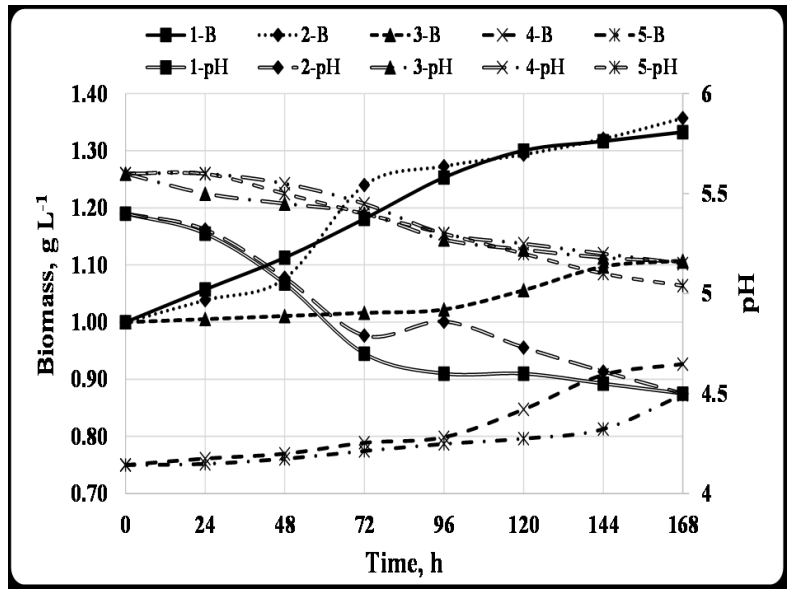

(b)

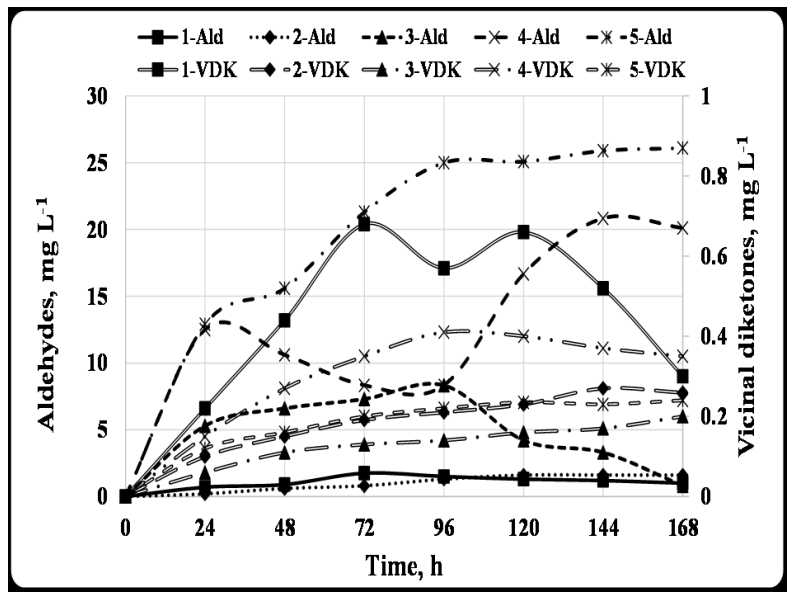

(d)

Fig. 1 Dynamics of the fermentation process for low-alcohol beer production; (a) real extract and alcohol, (b) biomass and pH, (c) esters and higher alcohols, (d) carbonyl compounds - aldehydes and vicinal diketones; Variants - according to Table 2; Legend: B - biomass; Alc - alcohol; $\mathrm{RE}$ - real extract; VDK - vicinal diketones; Ald - aldehydes; HA - higher alcohols; Est - esters; $\mathrm{pH}$ - pH value

In variant 2, the initial biomass concentration was the same as in the previous variant but the temperature was reduced to $7{ }^{\circ} \mathrm{C}$ (Fig. 1, Table 2). Fermentation started relatively slowly and it became vigorous after 96 hours. At the end of the fermentation the beer ethanol concentration was $0.8 \%(\mathrm{w} / \mathrm{w})$, which corresponded to apparent attenuation of $34 \%$. Although the apparent attenuation was similar to that of the previous variant, the amount of alcohol produced was twice as low. Therefore, it can be suggested that yeast utilized wort carbohydrates for preserving their vitality and stored carbohydrates in order to survive the stressful fermentation conditions. The biomass concentration changed to a small extent - for the entire fermentation process, it increased about $30-40 \%$. The decrease in temperature affected to a great extent the secondary metabolism of the cells. Low synthesis of carbonyl compounds was observed. At the end of the process, the aldehyde concentration did not exceed $2 \mathrm{mg} \mathrm{L}^{-1}$, and vicinal diketones concentration was about $0.25 \mathrm{mg} \mathrm{L}^{-1}$. The carbonyl compound reduction under these fermentation conditions was highly inhibited, but it did not affect the quality of the final beer due to the fact, that their synthesis was also reduced. The decrease in fermentation temperature strongly affected the beer higher alcohol synthesis as well. At this fermentation regime, it was difficult to accumulate more than $2 \mathrm{mg} \mathrm{L}^{-1}$, which was 5 to 7 times lower than the previous fermentation variant. It is interesting to note that ester synthesis was poorly affected by the decrease in the fermentation temperature. Their concentration was close to the one observed at the previous fermentation regime.

In variant 3 , the fermentation temperature was $5{ }^{\circ} \mathrm{C}$ and the initial biomass concentration was the same as the one in the previous two variants (Fig. 1, Table 2). The low fermentation temperature was the main reason for the fermentation to start after the $96^{\text {th }}$ hour. At the end of the process, the beer alcohol content was approximately $0.3 \%(\mathrm{w} / \mathrm{w})$. 
The low temperature provoked reduced biomass growth, therefore, its concentration increased by only $11 \%$. The apparent attenuation was only $6 \%$, i.e. most of the wort carbohydrates were not fermented. The reduction of the fermentation temperature to $5{ }^{\circ} \mathrm{C}$, despite of the high pitching rate, led to limited synthesis of the secondary metabolites. Unlike the previous regime, the decrease in the temperature affected the ester synthesis more strongly, resulting in approximately 1.5 times lower ester concentration than in the fermentation at $7^{\circ} \mathrm{C}$. Compared to conventional beer produced under optimal conditions with the same yeast strain $[13,15]$, the ester concentration was 5-10 times lower, which affected the flavor beer profile. Aldehyde synthesis was also inhibited and their maximal concentration in beer was $8 \mathrm{mg} \mathrm{L}^{-1}$. In contrast to the previous variants, aldehyde reduction was observed (Fig. 1 (d)). Higher alcohol synthesis was also hampered and their concentration in beer did not exceed 4-5 $\mathrm{mg} \mathrm{L}^{-1}$. In the case of vicinal diketones, the tendency for limited synthesis was also observed. Vicinal diketones reduction was not observed due to the low fermentation temperature. Their concentration in the final product was approximately $0.2 \mathrm{mg} \mathrm{L}^{-1}$.

\subsubsection{Fermentation kinetics}

In our previous studies [16-18], different types of models for describing the fermentation kinetics were discussed. In the present study of limited alcohol fermentation, the Monod model, supplemented with product inhibition showed the highest accuracy. The main reason was low glucose content of wort and therefore, the catabolic repression was not so enhanced. The low temperature increased the effect of the product inhibition on the cells, which was also commented in our previous studies [16-18]. Data is summarized in Table 3. The biomass specific growth rate was relatively low, and it did not exceed $0.026 \mathrm{~h}^{-1}$ for the three fermentation regimes (Table 3). Therefore, it led to the low ethanol production rate and low secondary metabolite production rates in beer. The low fermentation temperature resulted in very high $K_{S B}$ values in all

Table 3 Kinetic characteristics of fermentation for the production of low-alcohol and non-alcohol beers

\begin{tabular}{|c|c|c|c|c|c|c|c|c|c|}
\hline \multicolumn{10}{|c|}{ PRIMARY METABOLISM } \\
\hline \multirow{2}{*}{ Variant } & \multirow{2}{*}{\multicolumn{2}{|c|}{$\begin{array}{c}\mu_{\max } \\
\mathrm{h}^{-1}\end{array}$}} & \multirow{2}{*}{$\begin{array}{c}K_{S B} \\
\mathrm{~g} \mathrm{~L}^{-1}\end{array}$} & \multirow{2}{*}{$\begin{array}{c}q_{E \max } \\
\mathrm{g}(\mathrm{g} \mathrm{h})^{-1}\end{array}$} & \multirow{2}{*}{$\begin{array}{c}K_{S E} \\
\mathrm{~g} \mathrm{~L}^{-1}\end{array}$} & \multirow{2}{*}{$\begin{array}{c}Y_{B / R E} \\
-\end{array}$} & \multirow{2}{*}{$\begin{array}{c}Y_{A / R E} \\
-\end{array}$} & \multirow{2}{*}{$\begin{array}{l}K_{S B i} \\
\mathrm{~g} \mathrm{~L}^{-1}\end{array}$} & \multirow{2}{*}{$\begin{array}{l}K_{S E i} \\
\mathrm{~g} \mathrm{~L}^{-1}\end{array}$} \\
\hline & & & & & & & & & \\
\hline \multirow{2}{*}{1} & 0.026 & & 1211.0 & 0.016 & 2.061 & 0.035 & 0.085 & 0.297 & 0.042 \\
\hline & \multicolumn{3}{|c|}{$R^{2}=98.92 \%$} & \multicolumn{2}{|c|}{$R^{2}=99.46 \%$} & \multicolumn{2}{|c|}{$R^{2}=99.06 \%$} & - & - \\
\hline \multirow{2}{*}{2} & 0.026 & & 1081.7 & 0.004 & 2.053 & 0.028 & 0.033 & 0.341 & 0.341 \\
\hline & \multicolumn{3}{|c|}{$R^{2}=98.43 \%$} & \multicolumn{2}{|c|}{$R^{2}=98.96 \%$} & \multicolumn{2}{|c|}{$R^{2}=97.72 \%$} & - & - \\
\hline \multirow{2}{*}{3} & 0.012 & & 2093.7 & 0.001 & 1.652 & 0.037 & 0.046 & 0.417 & 0.711 \\
\hline & \multicolumn{3}{|c|}{$R^{2}=92.11 \%$} & \multicolumn{2}{|c|}{$R^{2}=93.15 \%$} & \multicolumn{2}{|c|}{$R^{2}=96.65 \%$} & - & - \\
\hline \multirow{2}{*}{4} & 0.023 & & 1790.7 & 0.005 & 1.0615 & 0.0331 & 0.0726 & 0.3711 & 0.6141 \\
\hline & \multicolumn{3}{|c|}{$R^{2}=95.35 \%$} & \multicolumn{2}{|c|}{$R^{2}=98.97 \%$} & \multicolumn{2}{|c|}{$R^{2}=96.33 \%$} & - & - \\
\hline \multirow{2}{*}{5} & 0.018 & & 2457.7 & 0.003 & 1.1135 & 0.0307 & 0.0878 & 0.3534 & 0.6140 \\
\hline & \multicolumn{3}{|c|}{$R^{2}=97.82 \%$} & \multicolumn{2}{|c|}{$R^{2}=98.36 \%$} & \multicolumn{2}{|c|}{$R^{2}=97.03 \%$} & - & - \\
\hline \multicolumn{10}{|c|}{ SECONDARY METABOLISM } \\
\hline & $Y_{\text {Ald }}$ & $k_{\text {Ald }}$ & & & & $Y_{V D K}$ & $K_{V D K}$ & - & - \\
\hline & & & & $\mathrm{ng}(\mathrm{g} \mathrm{h})^{-1}$ & & & & - & - \\
\hline 1 & 0.393 & 0.620 & & & & 0.008 & 0.025 & - & - \\
\hline 1 & $R^{2}=8$ & & $R^{2}=$ & $R^{2}=$ & $\%$ & $R^{2}=$ & $72 \%$ & - & - \\
\hline 2 & 0.410 & 0.802 & & & & 0.002 & 0.011 & - & - \\
\hline 2 & $R^{2}=96$ & & $R^{2}=$ & $R^{2}=$ & $\%$ & $R^{2}=$ & $23 \%$ & - & - \\
\hline 3 & 1.604 & 0.201 & & & & 0.004 & 0.012 & - & - \\
\hline$J$ & $R^{2}=88$ & & $R^{2}=$ & $R^{2}=$ & $\%$ & $R^{2}=$ & $35 \%$ & - & - \\
\hline 4 & 0.222 & 0.012 & & & & 0.009 & 0.029 & - & - \\
\hline 4 & $R^{2}=8$ & & $R^{2}=$ & $R^{2}=$ & $\%$ & $R^{2}=$ & $21 \%$ & - & - \\
\hline 5 & 1.035 & 0.029 & & & & 0.010 & 0.031 & - & - \\
\hline 3 & $R^{2}=85$ & & $R^{2}=$ & $R^{2}=$ & $\%$ & $R^{2}=$ & $21 \%$ & - & - \\
\hline
\end{tabular}


three models, which was the main reason for the low biomass maximum specific growth rate. Moreover, the product inhibition on biomass growth under these fermentation conditions started when the ethanol concentration was about $2 \mathrm{~g} \mathrm{~L}^{-1}$. The selected model described the extract consumption during fermentation with high accuracy. Typically, the model accuracy enhanced with the increase in fermentation temperature. This is due to the fact, that the model implied a monotone extract reduction, which required more time in a limited fermentation regime.

Arrested fermentation also led to a decrease in the yields coefficients of the major metabolite groups and their values did not exceed $0.5 \mathrm{mg}(\mathrm{g} \mathrm{h})^{-1}$ (with the exception of the yield coefficient for aldehydes), which in combination with the low biomass growth resulted in their low concentrations in the finished beer. Limited reduction of the carbonyl compounds was observed, which was mainly due to the low temperature.

The interesting data was the aldehyde yield coefficient at $5{ }^{\circ} \mathrm{C}\left(1.604 \mathrm{mg}(\mathrm{g} \mathrm{h})^{-1}\right)$. At this temperature, yeast cells tried to accumulate storage substances for preserving their vitality, which led to the increased production of acetaldehyde, which however did not transform into ethanol. Unfortunately, the model did not describe the aldehyde synthesis and reduction with high accuracy due to the low reduction rate. This affected the overall model accuracy as well and resulted in a higher error. In regard to vicinal diketones, the model described the experimental results with high precision. The model showed that the decrease in the fermentation temperature led not only to a decrease in their synthesis rates, but also to a decrease in the reduction rates.

\subsection{Fermentation at pitching rate of $10^{7} \mathrm{CFU} \mathrm{cm}^{-3}$}

The data from the first series of experiments showed that the fermentation temperature was crucial for the ethanol concentration in the finished beer. The other strategy for reducing the ethanol content is to decrease the biomass concentration. Therefore, two more fermentations were carried out at $7{ }^{\circ} \mathrm{C}$ and $10^{\circ} \mathrm{C}$ with an initial cell concentration of $10^{7} \mathrm{CFU} \mathrm{cm} \mathrm{cm}^{-3}$. At $5{ }^{\circ} \mathrm{C}$ it was found that fermentation did not start within the first 7 days and the secondary metabolite concentrations were below the detection threshold.

\subsubsection{Fermentation dynamics}

Fermentation data at $10^{\circ} \mathrm{C}$ and $10^{7} \mathrm{CFU} \mathrm{cm}^{-3}$ are shown in Fig. 1. The fermentation started relatively slowly, in the first 4 days only biomass grew (the increase in biomass concentration was about $30 \%$ ), the alcohol fermentation actually began afterwards. At the end of the fermentation the beer ethanol concentration was $0.8 \%(\mathrm{w} / \mathrm{w})$. The results for the secondary metabolite synthesis and reduction were very contradictory compared to the results for variant 1 . The low pitching rate was the main reason for the fact that the ester concentration was twice as low. Nevertheless, the higher alcohol concentration was comparable with the results for variant 1 . An increased synthesis of carbonyl compounds was observed. The aldehyde concentration was approximately $20 \mathrm{mg} \mathrm{L}^{-1}$. The synthesis of vicinal diketones was rather accelerated, because their synthesis is a part of an amino acid biosynthetic pathway. On the other hand, the low temperature combined with the low biomass concentration led to the slight reduction of diacetyl and 2,3-pentanedione. Therefore, the vicinal diketones concentration in the final beer was higher than the one in variant 1.

The last fermentation variant was at $7{ }^{\circ} \mathrm{C}$ and details of this fermentation process are presented in Fig. 1. In this case, the active fermentation started after about 72-96 hours and at the end of the process the ethanol concentration was approximately $0.45 \%(w / w)$. This guaranteed an apparent attenuation of about $9 \%$ or only $10 \%$ real degree of fermentation. Concerning the alcohol concentration, beer met the requirements for non-alcohol beverages. In the first 72-96 $\mathrm{h}$ the biomass concentration increased by about $30 \%$, which was necessary for the start of the active fermentation process. The dynamics of the synthesis and reduction of major secondary metabolites was not significantly different from the cases previously described. The combination of low temperature and low pitching rate led to a reduced synthesis of esters, higher alcohols and aldehydes. In the case of vicinal diketones and aldehydes, a decreased reduction was also observed, but it did not affect the final beer quality due to the low synthesis of these groups of substances.

\subsubsection{Fermentation kinetics}

Analogous to the previous regimes, the fermentation kinetics were evaluated at a pitching rate of $10^{7} \mathrm{CFU} \mathrm{cm}^{-3}$. The Monod model supplemented with product inhibition was used and the data obtained is summarized in Table 3.

Primary cell metabolism did not show any significant differences from the one observed at the previous three regimes. The data shows that the biomass specific growth rate was very low $\left(0.018-0.023 \mathrm{~h}^{-1}\right)$, but the decrease in the pitching rate led to about 5-10 times lower specific rates of ethanol production compared to the previous 
variants. Decreased pitching rate and low temperature were the main reasons the reduced ethanol production. The data in Table 3 shows that the substrate utilization was inhibited at these low fermentation temperatures, which was confirmed by high values of the $K_{S B}$ coefficients. Under these fermentation conditions, the biomass and ethanol yield coefficients were also rather low. Moreover, the data obtained confirmed that these regimes were suitable for the production of low-alcohol and even non-alcohol beer, since the selected combination of temperature and pitching rate resulted in the accumulation of less ethanol in the final product. The wort composition in regard to fermentable sugar content also helped the production of beer with reduced alcohol content.

The results for ester and higher alcohol synthesis of

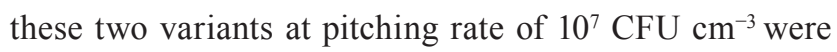
very interesting. The decrease in the pitching rate led to the increase in the yield coefficients for esters and higher alcohols. Therefore, fruity notes (banana, apple) were found in the sensorial evaluation of the laboratory produced beers. It is interesting to note that the decrease in the temperature resulted in 6-fold increase in the yield coefficient of higher alcohols, which also reflected to the higher alcohols concentrations in beer.

The decrease in the pitching rate led to the increase in the vicinal diketones yield and reduction coefficients. Nevertheless, the model accuracy increased with the decrease in the fermentation temperature. However, vicinal diketones concentrations in the beer were relatively low and they were up to $0.25-0.35 \mathrm{mg} \mathrm{L}^{-1}$.

In regard to aldehydes, the yield coefficient at $7{ }^{\circ} \mathrm{C}$ was almost 5 times higher than the same parameter in fermentation at $10{ }^{\circ} \mathrm{C}$, which can be explained by the cells attempts for adaptation to the stress conditions of fermentation. The higher aldehyde reduction coefficient at $7{ }^{\circ} \mathrm{C}$ was the main reason for almost equal aldehyde concentration in beer - about $20-25 \mathrm{mg} \mathrm{L}^{-1}$.

Unlike the previous three fermentation regimes, the decrease in the pitching rate and the fermentation temperature positively affected the model accuracy, especially those for the secondary metabolism of the cells. Therefore, the error data of the primary and secondary cell metabolism models were lower.

\subsection{Sensory assessments}

The aroma and taste of beer with reduced alcohol content is usually rather different from its fully fermented counterpart and this beer often suffers from different flavor problems [1]. Therefore, sensory assessments of beers obtained were carried out and the data is presented on Fig. 2. Different variants had their individual sensorial characteristics, but the panel preferred mostly variant 1 . Beer variant 1 received highest scores in all of the categories except carbonization. The panel evaluated it highly because its sensory profile was closer to the one of conventional beer. The least preferred sample was variant 5 .

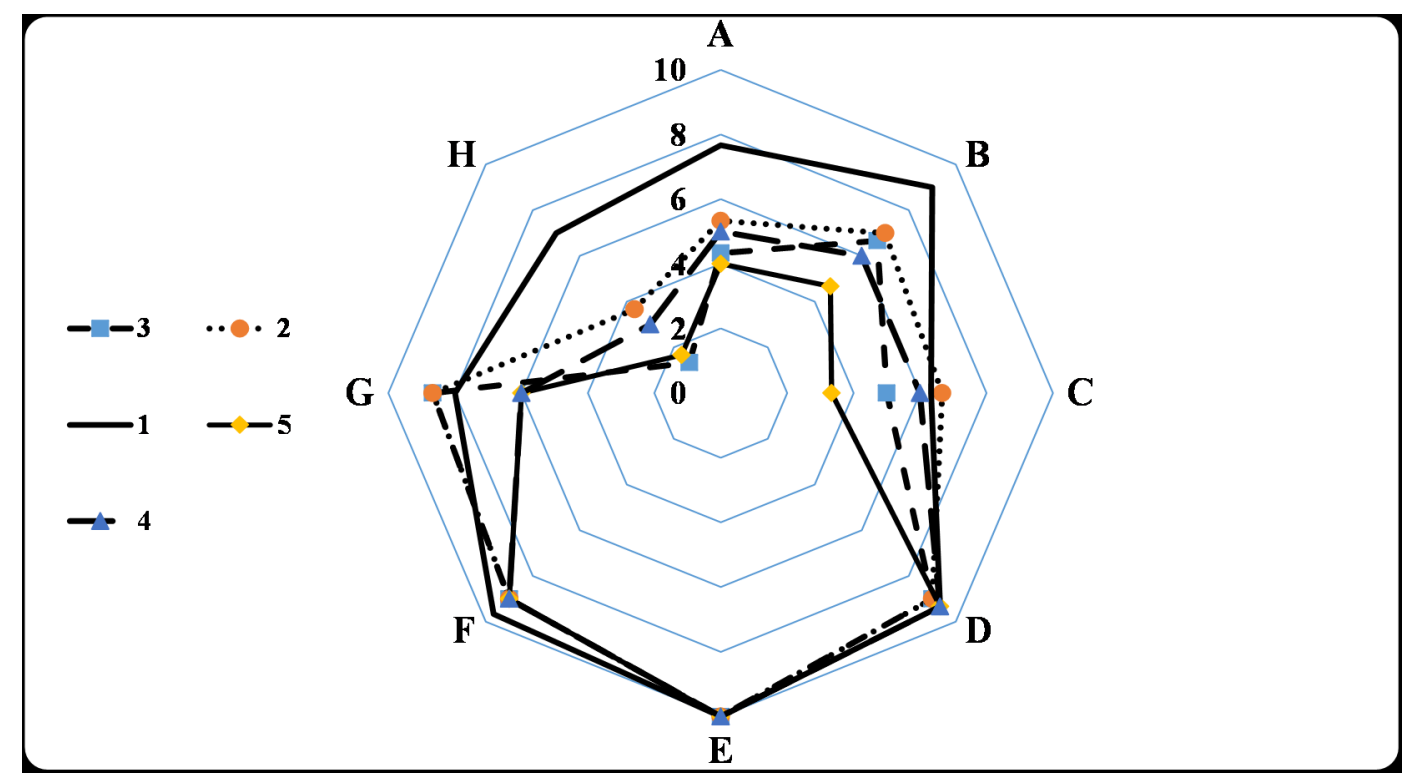

Fig. 2 Sensory assessment of experiment beer variants; Legend: A - flower notes; B - fruity notes; C - aroma intensity; D - aroma purity; $\mathrm{E}$ - body structure; F - malty tones; $\mathrm{G}$ - carbonization; $\mathrm{H}$ - feeling of alcohol 


\subsection{Discussion}

The proposed study examined 5 fermentation regimes, each with its specific advantages and disadvantages. Generally, the choice comes to the regimes with higher cell content and at temperatures of $7-10{ }^{\circ} \mathrm{C}$, with the amount of alcohol and extract in the beer being adjusted by dilution with carbonated water.

Compared to other methods and modes used for obtaining beer with reduced alcohol content, the proposed method is characterized by a number of advantages - it uses the standardized equipment of breweries, allows the use of conventional yeast, etc. In the present case, the limitation of the alcohol fermentation was estimated by the kinetic parameters, which allows the production process to be optimized. Existing technologies for the production of beer with reduced alcohol content are based on the limitation of alcohol fermentation. As already pointed out, the main difficulty with limited fermentation is the limited metabolite synthesis, which affects the final product. In practice, different approaches are used to deal with this problem. Most often, it is solved by producing beer with mash with high initial mash extract, which provokes increased production of esters and higher alcohols. The resulting beer is then diluted with carbonated water to the appropriate concentrations with respect to the ethanol and the extract [1,4-8]. As can be seen, the proposed operational modes lead to the production of beer with an alcohol content, which does not require significant dilution to the corresponding alcohol content.

Another way to improve the beer organoleptic profile is by fermentation at higher temperatures and reduction of the mash oxygen content, which increases the amount of esters produced, when yeast is used to produce ale. Increasing the initial fermentation temperature increases the fermentation rate but provokes the accumulation of more volatile components and vicinal diketones. Comparison of different yeast strains shows that more aliphatic alcohols accumulate at low fermentation rates, while the use of top-fermenting strains leads to the increase in the diacetyl amount as well. After fermentation discontinuation at an alcohol content of less than $0.5 \%$ vol., it is necessary for the beer to mature for about 10 days at $0-1{ }^{\circ} \mathrm{C}$ in order to remove the sulfur components. The resulting low-alcohol beer is then filtered, carbonized, stabilized, and sterilized [1, 4-8]. In the cases under consideration, the synthesis and reduction of secondary metabolites can be regulated by changes in temperature and inoculum concentration, which significantly reduces the risks described.

The proposed method is close to the so-called Cold Contact Process (CCP), in which the beer is produced by fermentation of low-extract beer mash $(6 \%)$ at $0-1{ }^{\circ} \mathrm{C}$ and initial $\mathrm{pH}=4$ (after acidification with lactic acid). Data show that relatively normal amounts of ethanol and metabolites accumulate in beer under these conditions $[1,19,20]$. The main difference is the use of wort with extract content that meets the standardized indicators for ordinary beer but has a reduced degree of fermentation. The choice of fermentation regimes should be related to the equipment available, the mash composition and the yeast strain. The improvement of the beer organoleptic profile can also be done by other methods [1].

\section{Conclusion}

Each of the investigated 5 regimes for low-alcohol and non-alcohol beer production had its specific advantages and disadvantages. However, the combination of fermentation temperature of $10{ }^{\circ} \mathrm{C}$ and pitching rate of $10^{9} \mathrm{CFU} \mathrm{\textrm {cm } ^ { - 3 }}$ led to the production of beer, which was evaluated with highest scores by the tasting panel because the secondary metabolite concentrations were close to the greatest extent to the ones of conventional pale beer, compared to the other variants. Although the alcohol concentration was close to the upper limit for low-alcohol beer, the beer can be diluted with carbonated water as it is made for the commercial high gravity beers.

It has been found that the alcohol fermentation process is best described by the Monod model, supplemented by product inhibition. Inhibition increases with decreasing the fermentation temperature, which in combination with the low concentration of fermentable sugars, is the reason for the limited alcohol synthesis.

\section{Acknowledgement}

The research has been funded under Project No KP-06-M27/3 "Technological and microbiological approaches for the production of new types low-alcohol and non-alcoholic drinks with increased biological value" of the National Science Fund, Bulgaria. This research has been partially supported by the National Scientific Fund of Bulgaria under the Grant КП-06-H32/3 "Interactive System for Education in Modelling and Control of Bioprocesses (InSEMCoBio)". 


\section{References}

[1] Brányik, T., Silva, D. P., Baszczyňski, M., Lehnert, R., Almeida e Silva, J. B. "A review of methods of low alcohol and alcohol-free beer production", Journal of Food Engineering, 108, pp. 493-506, 2012.

https://doi.org/10.1016/j.jfoodeng.2011.09.020

[2] Meussdoerffer, F. G. "A Comprehensive History of Beer Brewing", In: Esslinger, H. M. (ed.) Handbook of Brewing: Processes, Technology, Markets, Wiley-VCH Verlag GmbH \& Co., Weinheim, Germany, 2009, pp. 1-42. https://doi.org/10.1002/9783527623488.ch1

[3] Silva, D. P., Brányik, T., Teixeira, J. A., Almeida E Silva, J. B. "Cervejas sem álcool" (Alcohol-free beer), In: Venturini Filho, W. G. (ed.) Bebidas Alcoólicas: Ciência e Tecnologia, Edgard Blucher Ltda, São Paulo, Brazil, pp. 69-83, 2010. (in Portuguese)

[4] Muller, R. E. "The production of low-alcohol and alcohol-free beers by limited fermentations", Ferment, 3(4), pp. 224-230, 1990.

[5] Muller, R. E. "The Effects of Mashing Temperature and Mash Thickness on Wort Carbohydrate Composition", Journal of the Institute of Brewing, 97(2), pp. 85-92, 1991.

https://doi.org/10.1002/j.2050-0416.1991.tb01055.x

[6] Perpete, P., Collin, S. "State of the art in low-alcohol beer production", Cerevisia: Belgian Journal of Brewing and Biotechnology, 24(1), pp. 27-33, 1999.

[7] Perpète, P., Collin, S. "Fate of the worty flavours in a cold contact fermentation", Food Chemistry, 66(3), pp. 359-363, 1999. https://doi.org/10.1016/S0308-8146(99)00085-0

[8] Perpète, P., Collin, S. "Influence of beer ethanol content on the wort flavour perception", Food Chemistry, 71(3), pp. 379-385, 2000. https://doi.org/10.1016/S0308-8146(00)00179-5

[9] Ivanov, K., Petelkov, I., Shopska, V., Denkova, R., Gochev, V., Kostov, G. "Investigation of mashing regimes for low-alcohol beer production", Journal of the Institute of Brewing, 122(3), pp. 508- 516, 2016. https://doi.org/10.1002/jib.351

[10] Knowledge Center Brew Up by the Brewers of Europe "Analytica EBC", [online] Available at: https://brewup.eu/ebc-analytica/ search [Accessed: 20 January 2020]

[11] Marinov, M. "Ръководство за анализ на високоалкохолни напитки и спирт" (Practical Guide for Analysis and Control of Alcoholic Beverages and Ethanol), Academy Publisher of UFT, Plovdiv, Bulgaria, 2010. (in Bulgarian)
[12] Parcunev, I., Naydenova, V., Kostov, G., Yanakiev, Y., Popova, Z., Kaneva, M., Ignatov, I. "Modeling of Alcohol Fermentation in Brewing - Some Practical Approaches", In: 26th European Conference on Modelling and Simulation, Koblenz, Germany, 2012, pp. 434-440.

https://doi.org/10.7148/2012-0434-0440

[13] Petelkov, I., Lyubenova, V., Zlatkova, A., Shopska, V., Denkova, R., Kaneva, M., Kostov, G. "Encapsulation of brewing yeast in alginate/chitosan matrix: Kinetic characteristics of the fermentation process at a constant fermentation temperature", Comptes rendus de l'Académie bulgare des Sciences, 69(10), pp. 1355-1363, 2016.

[14] Petelkov, I., Shopska, V., Denkova-Kostova, R., Kostov, G., Lyubenova, V. "Investigation of Different Regimes of Beer Fermentation with Free and Immobilized Cells", Periodica Polytechnica Chemical Engineering, 64(2), pp. 162-171, 2020. https://doi.org/10.3311/PPch.13845

[15] Boulton, C., Quain, D. "The Biochemistry of Fermentation", In: Boulton, C., Quain, D. (eds.) Brewing Yeast and Fermentation, Blackwell Science, Oxford, UK, 2007, pp. 69-142. https://doi.org/10.1002/9780470999417.ch3

[16] Shopska, V., Denkova, R., Kostov, G. "Beer Production with Encapsulated Yeast Cells", In: Salazar, W. H. (ed.) Beer: Production, Consumption and Health Effects, 1st ed., Nova Science Publishers Inc., Hauppauge, New York, NY, USA, 2016, pp. 27-100.

[17] Naydenova, V. "Проучване на възможностите за получаване на пиво с имобилизирани дрожди" (A Study of Possibilities for Beer Production with Immobilized Yeast Cells), PhD Thesis, University of Food Technologies, 2014. (in Bulgarian)

[18] Kostov, G., Denkova-Kostova, R., Shopska, V., Goranov, B. "Analytical Approaches to Determine the Specific Biomass Growth Rate in Brewing", In: 33th European Conference on Modelling and Simulation, Caserta, Italy, 2019, pp. 125-131. https://doi.org/10.7148/2019-0125

[19] Schur, F., Brauerei Feldschlosschen, Switzerland "Process for the preparation of alcohol-free drinks with a yeast aroma", US Patent 4,746,518, 1988.

[20] Montanari, L., Marconi, O., Mayer, H., Fantozzi, P. "Production of alcohol-free beer", In: Preedy, V. R. (ed.) Beer in Health and Disease Prevention, Elsevier, Burlington, MA, USA, 2009, pp. 61-75. 